\title{
Expression of nerve growth factor and brain-derived neurotrophic factor in astrocytomas
}

\author{
TING-TING LIU ${ }^{1,2^{*}}$, HAO WANG ${ }^{3 *}$, FENG JUAN WANG ${ }^{2}$, YU FENG XI ${ }^{4}$ and LI HUA CHEN ${ }^{2}$ \\ ${ }^{1}$ Department of Internal Medicine, No. 4 West China Teaching Hospital, Sichuan University; ${ }^{2}$ Department of Hematology and \\ Research Laboratory of Hematology, West China Hospital, Sichuan University; ${ }^{3}$ Department of Gastrointestinal Surgery, \\ The First Affiliated Hospital of Chengdu Medical College, Chengdu Medical College; ${ }^{4}$ State Key Laboratory of Biotherapy and \\ Cancer Center, West China Hospital, West China Medical School, Sichuan University, Chengdu, Sichuan 610041, P.R. China
}

Received June 30, 2016; Accepted May 18, 2017

DOI: $10.3892 / \mathrm{ol} .2017 .7333$

\begin{abstract}
Neurotrophic factors (NTFs) are well known to serve critical functions in neural survival, neurite growth and cell differentiation in vivo and in vitro. Previous progress has indicated that nerve growth factor (NGF) and brain-derived neurotrophic factor (BDNF), two NTF family members, may be involved in the process of tumor progression. In the present study, the expression of NGF and BDNF was detected using immunohistochemistry on 70 adult astrocytoma samples collected from distinct locations as well as of various pathological grades, with an additional 15 samples being collected from normal adult brain tissue to be used as controls. NGF and BDNF were identified to be expressed in all samples, and their positive cell expression rates in astrocytomas demonstrated a significant increase compared with that in the normal controls $(\mathrm{P}<0.05)$, particularly in grade III $(\mathrm{P}<0.05)$. In addition, the expression of NGF and BDNF exhibited a gradual decrease ranging from the temporal lobe, parietal lobe and cerebellum to the frontal lobe $(\mathrm{P}<0.05)$. The results of the present study suggest that the expression of NGF and BDNF is increased in astrocytomas, which is associated with the pathological grade and the astrocytoma location.
\end{abstract}

\section{Introduction}

Neurotrophic factors (NTFs) are endogenously produced as biological mediators that regulate neural growth, differentiation and apoptosis in the development of the nervous system (1-3).

Correspondence to: Dr Hao Wang, Department of Gastrointestinal Surgery, The First Affiliated Hospital of Chengdu Medical College, Chengdu Medical College, 4 Baoguang Road, Xindu, Chengdu, Sichuan 610041, P.R. China

E-mail: hw0616@sina.com

*Contributed equally

Key words: nerve growth factor, brain-derived neurotrophic factor, astrocytoma
Nerve growth factor (NGF) is the most well-known and best characterized member of the neurotrophin family $(1,4,5)$, which is structurally similar to other growth factors including brain-derived neurotrophic factor (BDNF) $(1,6,7)$. NGF is produced by cells located in several brain regions, and is expressed at the highest levels in the hippocampus, cortex $(1,5,8)$, cerebellum and spinal cord $(1,7,9)$. NGF, and receptors, tropomyosin receptor kinase $\mathrm{A}$ (TrkA) and $\mathrm{p} 75$ nerve growth factor receptors, exhibit pleiotropic effects in inducing cell differentiation, preventing apoptosis and supporting cell survival in neuronal progenitor cells and immature neurons of the central nervous system (CNS) and peripheral nervous system $(1,6,10,11)$. Previous studies have demonstrated that NGF and TrkA may contribute an important role in the growth modulation of human tumor cells (12). BDNF, the second member of the NTFs to be identified, is widely distributed in the CNS (13-17), and is produced primarily in the hippocampus, thalamus and cerebellum $(1,18)$. BDNF serves an essential role in maintaining and modulating the physiological functions of neurons and promoting the growth, survival and metastasis of a variety of tumor cells through binding to its receptors, tropomyosin receptor kinase $\mathrm{B}(\operatorname{TrkB})$ and $\mathrm{p} 75$ nerve growth factor receptors (19-24).

Previous studies have suggested that NTFs and their receptors are associated with cell maturation and tumoral cell apoptosis $(1,25,26)$. In contrast, a number of growth factors and signaling molecules appear to represent specific markers for distinct histological types of tumors and may be involved in the differentiation process of neoplasms (1). In accordance with these distinct mechanisms of action of NTFs, the aim of the present study was to examine the expression of NGF and BDNF in astrocytomas, and to investigate the association between NGF, BDNF, pathological grading and location, as well as tumorigenesis of astrocytomas.

\section{Materials and methods}

Tissue samples. A total of 70 clinical astrocytoma samples (39 male and 31 female, age range $21-75$ years; median age 47.3 years) were collected from The First Affiliated Hospital of Chengdu Medical College (Chengdu, China) from February 2006 to May 2013. All procedures were performed 
according to an Institutional Review Board (IRB)-approved protocol. These samples, based on their pathological grades, were classified as 10 cases of grade I, 24 of grade II, 26 of grade III and 10 of grade IV. Conversely, grouped according to the location of astrocytomas, there were 20 samples from the temporal lobe, 16 from the frontal lobe, 18 from the parietal lobe and 16 from the cerebellum. In addition, 15 normal brain specimens were obtained as controls from the normal brain tissues ( 7 samples from the temporal lobe, 6 from the frontal lobe, 1 from the parietal lobe and 1 from the cerebellum) of patients who underwent surgery for cerebral trauma. The expression of NGF and BDNF was examined in different locations in astrocytomas, not in normal brain tissues, because it is relatively difficult to obtain the samples of normal brain tissues from locations other than the temporal lobe and frontal lobe.

The samples were obtained from patients during surgery, fixed in $10 \%$ neutralized formalin for $12 \mathrm{~h}$ at room temperature within $24 \mathrm{~h}$ of being obtained and subsequently dehydrated in graded ethanol, embedded in paraffin and then sliced into serial $4 \mu \mathrm{m}$ sections. Each specimen was cut into 3 sections, which were used for immunohistochemistry, stained with hematoxylin and eosin together with a negative control (PBS).

Reagents. A rabbit anti-human NGF polyclonal antibody (cat. no. MFCD07370460; 1:200 dilution) and a rabbit anti-human BDNF polyclonal antibody (cat. no. SAB2108004; 1:200 dilution) were purchased from Sigma-Aldrich; Merck KGaA (Darmstadt, Germany). Streptavidin-Peroxidase kit (cat. no. kit-9710) and diaminobenzidine (DAB) chromogenic reagent kit (DAB-2031) were purchased from Maixin New Biology (Fuzhou, Fujian, China).

Immunohistochemistry. The sections were deparaffinized in xylene, rehydrated using serial dilutions of ethanol and washed three times in $0.1 \mathrm{M}$ PBS for $5 \mathrm{~min}$ each time. Antigen retrieval was performed for $15 \mathrm{~min}$ at $100^{\circ} \mathrm{C}$ in citrate buffer $(10 \mathrm{mmol} / \mathrm{l} ; \mathrm{pH}$ 6.0) in a microwave oven. The sections were then washed three times in $0.1 \mathrm{M}$ PBS for 5 min each, and incubated at room temperature in $0.2 \%$ hydrogen peroxide for $20 \mathrm{~min}$ to block the action of any endogenous peroxidase. Following a further three $5 \mathrm{~min}$ washes in $0.1 \mathrm{M}$ PBS, normal goat serum was added for $20 \mathrm{~min}$ at $37^{\circ} \mathrm{C}$ prior to incubation overnight at $4^{\circ} \mathrm{C}$ in one of the primary antibody solutions (polyclonal neurotrophin antisera for NGF and BDNF). Subsequently, the sections were washed in $0.1 \mathrm{M}$ PBS three times for 5 min each prior to incubation with labeled streptavidin-biotin for $30 \mathrm{~min}$ at room temperature according to the manufacturer's protocol in Maixin New Biology. Thereafter, they were washed in 0.1 M PBS again, and DAB chromogenic reagent was added in order to observe the distribution of NGF and BDNF according to the manufacturer's protocol (Maixin New Biology). Finally, all sections were mounted, dehydrated, placed on coverslips and observed under a light microscope at magnification, $\mathrm{x} 200$.

The tumor specimens were used as the experimental group (grade I-IV groups) with the normal brain tissue used as the control group. Instead of using the primary antibody as a negative control, PBS was used for both experimental and normal groups.
Table I. Expression of NGF and BDNF in normal brain tissue and astrocytomas of distinct pathological grades.

\begin{tabular}{lccc}
\hline Grade & Cases & $\begin{array}{c}\text { NGF } \\
\text { expression, \% }\end{array}$ & $\begin{array}{c}\text { BDNF } \\
\text { expression, \% }\end{array}$ \\
\hline Normal tissues & 15 & $7.06 \pm 0.95^{\mathrm{a}}$ & $5.98 \pm 0.49^{\mathrm{a}}$ \\
I & 10 & $16.56 \pm 4.56^{\mathrm{a}}$ & $11.24 \pm 2.05^{\mathrm{a}}$ \\
II & 26 & $32.45 \pm 10.07^{\mathrm{a}}$ & $18.23 \pm 4.96^{\mathrm{a}}$ \\
III & 24 & $40.91 \pm 26.40^{\mathrm{a}}$ & $21.44 \pm 3.35^{\mathrm{a}}$ \\
IV & 10 & $24.71 \pm 8.28^{\mathrm{a}}$ & $15.39 \pm 2.01^{\mathrm{a}}$ \\
\hline
\end{tabular}

${ }^{a}$ Statistically significant difference among compared groups $(\mathrm{P}<0.05)$. $\mathrm{NGF}$, nerve growth factor; BDNF, brain-derived neurotrophic factor.

Table II. Expression of NGF and BDNF from distinct astrocytoma locations.

\begin{tabular}{lccc}
\hline Region & Cases & $\begin{array}{c}\text { NGF } \\
\text { expression, \% }\end{array}$ & $\begin{array}{c}\text { BDNF } \\
\text { expression, \% }\end{array}$ \\
\hline Temporal lobe & 18 & $42.57 \pm 13.57^{\mathrm{a}}$ & $24.19 \pm 7.12^{\mathrm{a}}$ \\
Parietal lobe & 16 & $35.62 \pm 9.47^{\mathrm{a}}$ & $20.09 \pm 4.56^{\mathrm{a}}$ \\
Cerebellum & 16 & $28.67 \pm 6.47^{\mathrm{a}}$ & $16.17 \pm 4.29^{\mathrm{a}}$ \\
Frontal lobe & 20 & $21.45 \pm 7.56^{\mathrm{a}}$ & $16.17 \pm 4.29^{\mathrm{a}}$ \\
\hline
\end{tabular}

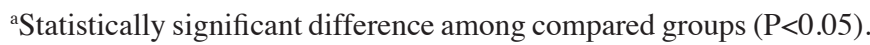
NGF, nerve growth factor; BDNF, brain-derived neurotrophic factor.

Microscopic examination. Each immunohistochemistry section was observed under a light microscope (XS-212; Nanjing Jiangnan Novel Optics, Co., Ltd., Nanjing, China). The number of positively stained cells was determined from 10 fields of view at magnification, $x 400$ and the mean positive cell numbers were calculated independently by two pathologists from the Department of Pathology at The First Affiliated Hospital of Chengdu Medical College. Subsequently, the total cell number in the same fields of view was determined and the mean number of cells for each section was calculated.

Expression rate of positive cells=(number of positive cells/ number of total cells) $\mathrm{x} 100 \%$.

Statistical analysis. The data and the categorical variables were analyzed and compared using analysis of variance (ANOVA) followed by a Student-Newman-Keuls post-hoc test, using the SPSS software package for Windows (version 11.5; SPSS, Inc., Chicago, IL, USA). Data are expressed as the mean \pm standard deviation and $\mathrm{P}<0.05$ was considered to indicate a statistically significant difference.

\section{Results}

Expression of NGF and BDNF in normal brain tissues and in astrocytomas of distinct pathological grades. The immunopositive products of NGF (Fig. 1) and BDNF (Fig. 2) were observed in the normal brain tissues and in the astrocytomas. 

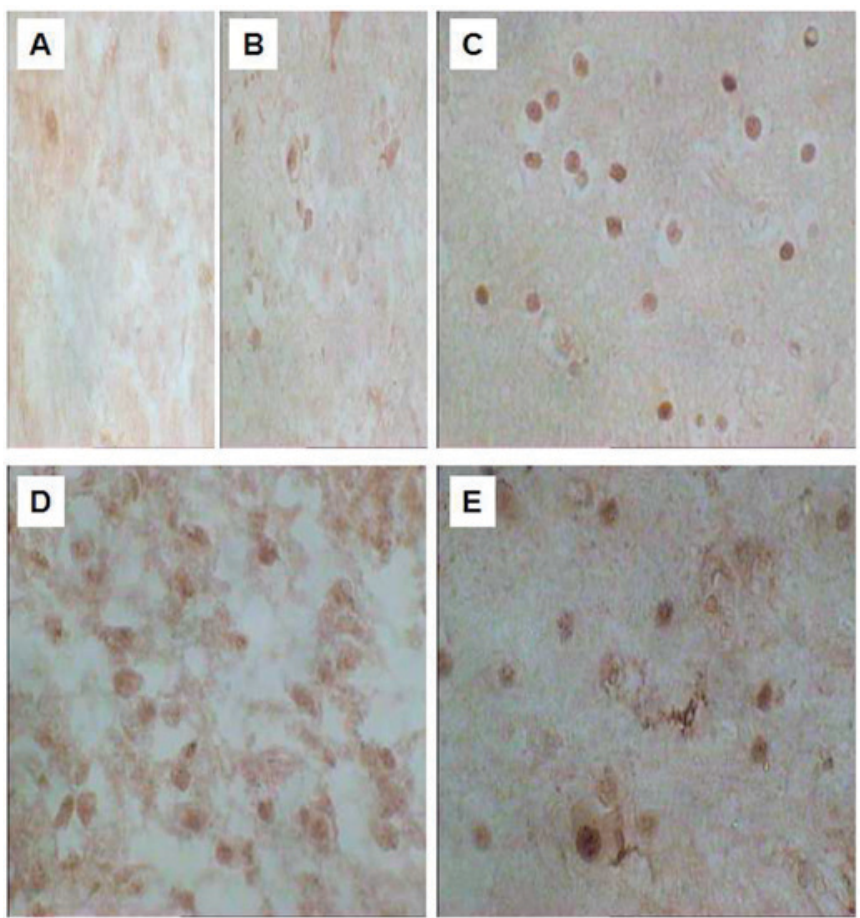

Figure 1. NGF was observed in the cytoplasm and nucleus of normal brain tissue and astrocytomas, but primarily in the nucleus. The expression of NGF in (A) normal brain tissue, (B) grade I astrocytoma, (C) grade II astrocytoma, (D) grade III astrocytoma and (E) grade IV astrocytoma. Magnification, $\mathrm{x} 400$ NGF, nerve growth factor.
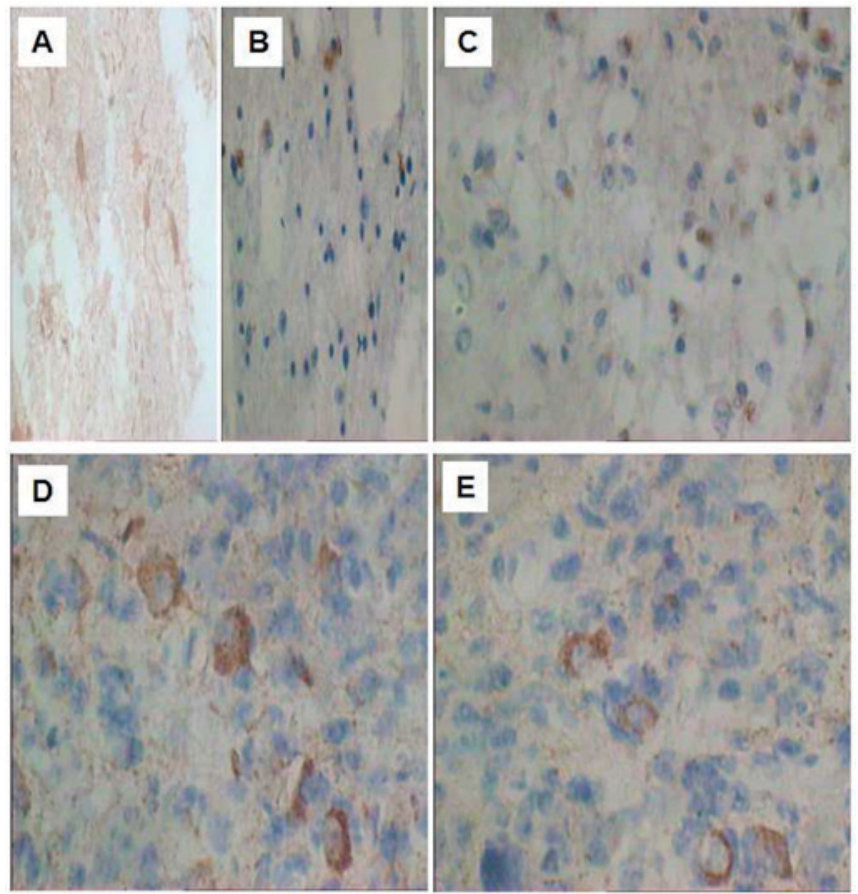

Figure 2. BDNF was observed in the cytoplasm of normal brain tissues and astrocytomas. The expression of the BDNF in (A) normal brain tissue (magnification, x400), (B) grade I astrocytoma (magnification, x200), (C) grade II astrocytoma magnification, x200), (D) grade III astrocytoma (magnification, $\mathrm{x} 400$ ) and (E) grade IV astrocytoma (magnification, $\mathrm{x} 400$ ). BDNF, brain-derived neurotrophic factor.

The positive expression rate of NGF in astrocytomas was significantly increased compared with that in normal brain tissue $(\mathrm{P}<0.05)$. Furthermore, there was a statistically significant difference $(\mathrm{P}<0.05)$ in the expression rate of NGF- and BDNF-positive cells between distinct pathological grades of astrocytomas, with the highest expression observed in grade III (Table I; P<0.05).

The staining of NGF-positive cells was observed in the cytoplasm and nucleus, but primarily in the nucleus (Fig. 1). However, the staining of BDNF-positive cells was primarily observed in the cytoplasm (Fig. 2).

Expression of NGF and BDNF in astrocytomas from distinct locations. NGF and BDNF were expressed in astrocytomas from all locations; however, the expression rate of positive cells was statistically different $(\mathrm{P}<0.05)$ between distinct locations. The sources may be ranked in decreasing order of expression rate from the temporal lobe, parietal lobe and cerebellum to the frontal lobe (Table II; $\mathrm{P}<0.05$ ).

\section{Discussion}

NTFs serve a crucial role in a variety of distinct types of brain cell and in their differentiation processes (1,7-9). Previous studies have suggested that NTFs may be associated with certain biochemical and molecular mechanisms of carcinogenesis and growth signaling pathways, undergoing deregulation in numerous human malignancies, including neuroectodermal brain tumors, testicular germ cell tumors and prostate cancer (1,27-30). However, little has been known previously regarding the association between the expression of NGF and BDNF, pathological grading, and region of astrocytomas. The results of the present study demonstrated that NGF and BDNF levels were increased in astrocytomas compared with the controls, and were associated with the pathological grading and region of astrocytomas.

The results of the present study revealed that NGF and BDNF were overexpressed in astrocytomas and were associated with the location, generation, progression and pathological grade of the astrocytoma. Goustin et al (31) demonstrated that the amount of serum required in the process of tumor cell growth was decreased and there was a ubiquitous decreasing demand for growth factors from extrinsic sources in numerous types of cancer cell. Specifically, the decrease may be restored via activating the autocrine pathway, altering the synthesis of growth factor receptors and activating the post-receptor machinery (31). The results of the present study demonstrated that the expression of NGF and BDNF were significantly upregulated gradually from normal tissues to grade I, II and III astrocytomas. This suggested that an autocrine pathway may be activated in the process of astrocytoma tumorigenesis and the proliferation of cancer cells was accelerated by synthesizing autocrine growth factors. However, the expression of NGF and BDNF in grade IV astrocytomas decreased suddenly, which was significantly different from in grade I, II and III astrocytomas. This may have resulted from the tumor cells no longer requiring the activation of the NGF receptor pathway. Therefore, it is hypothesized that the overexpression of NGF and BDNF may be the early and middle events in astrocytoma tumorigenesis.

In normal brain, the in situ hybridization experiment verified that NGF mRNA is expressed in pyramidal cells, granular cells in the hippocampus, stellate cells, oligodendrocytes and 
certain cortical neurons. NGF is produced by cells located in a number of brain regions, and is expressed in the highest amounts in the hippocampus and cortex $(5,8)$. BDNF is produced primarily in the hippocampus, thalamus and cerebellum (18). The results of the present study identified that the expression of NGF and BDNF exhibited a statistically significant gradual decrease in the temporal lobe near the hippocampus, parietal lobe near the cerebral cortex, cerebellum and frontal lobe respectively. This phenomenon suggested that hippocampal and cortical tissues are activated to synthesize and release NGF and BDNF in the formation of astrocytomas.

NGF and BDNF are able to promote the survival and differentiation of neurons and contribute a key role in the reparative process of injured nerve cells. Multiple previous studies have also demonstrated that NGF and BDNF and their receptors are associated with tumor biology, behavior and progression $(1,29,32)$, although the underlying molecular mechanism of tumor progression remains unclear. Zhu et al (33) identified that NGF and TrkA were notably overexpressed in pancreatic cancer tissues compared with in normal pancreatic tissue, and increased NGF/TrkA expression was associated with the invasion and the pain caused by the tumor, although it was not associated with the degree of tumor differentiation or grading. Furthermore, NGF is notably downregulated in esophageal carcinoma tissues and is associated with the degree of tumor differentiation as well as its pathological grades. Low TrkA expression was associated with advanced tumor stage (34). In addition, NGF mRNA and protein are expressed in breast cancer, but not in normal breast tissue, and may be inhibited by NGF-neutralizing antibodies or a TrkA-blocking agent such as K-252a (35). A study by Breit et al (36) demonstrated that TrkA was associated with the differentiation, generation and angiogenesis of neuroblastoma (NB). Another study demonstrated that the TrkA gene is a good prognostic marker in NB and inhibited NB hyperplasia, induced benign differentiation and affected the growth of blood vessels of NB (37). NGF and TrkA were also observed to be decreased, whereas p75 was increased in childhood low-grade astrocytomas and ependymoma tissue (1). Similarly, BDNF and TrkB are expressed in multiple myeloma cell lines (38). BDNF was also identified to induce cell migration and cell proliferation in cultured human ovarian cancer cells (39). In addition, the level of BDNF in serum was significantly associated with tumor size in patients with hepatocellular carcinoma (19). These studies and the results of the present study revealed that NGF and BDNF, with receptors, participate in tumorigenesis.

The results of the present study indicate that NGF and BDNF overexpression in astrocytomas and their positive cell rate may be ranked in decreasing order from grade III, II, IV and I, and, finally, normal brain tissue. This suggests that NGF and BDNF are involved in the process of astrocytoma tumorigenesis, and the overexpression of NGF and BDNF may occur at early and middle stages of astrocytoma formation. The results of the present study also identified that the closer to the hippocampal and cortical areas, the higher the expression rate of positive cells for NGF and BDNF in astrocytomas. This may be that the astrocytoma stimulates astrocyte cells to secrete NGF and BDNF during the process of astrocytoma formation, and the hippocampal and cortical regions produce growth factors including NGF and BDNF.
In conclusion, the results of the present study suggest that NGF and BDNF are overexpressed in astrocytomas, with associations with the pathological grade as well as the location of the astrocytomas.

\section{Acknowledgements}

The authors would like to thank Professor Yuan Chun Fan and Dr Liang Jiang, from the Department of Pathology at The First Affiliated Hospital of Chengdu Medical College (Chengdu, China) for their technical assistance and helpful discussion.

\section{References}

1. Chiaretti A, Aloe L, Antonelli A, Ruggiero A, Piastra M, Riccardi R, Tamburrini G and Di Rocco C: Neurotrophic factor expression in childhood low-grade astrocytomas and ependymomas. Childs Nerv Syst 20: 412-419, 2004.

2. Aloe L, Tirassa P and Bracci-Laudiero L: Nerve growth factor in neurological and non-neurological diseases: Basic findings and emerging pharmacological prospectives. Curr Pharm Des 7: 113-123, 2001.

3. Drago J, Kilpatrick TJ, Koblar SA and Talman PS: Growth factor: Potential therapeutic applications in neurology. J Neurol Neurosurg Psychiatry 57: 1445-1450, 1994.

4. Levi-Montalcini R: The nerve growth factor 35 years later. Science 237: 1154-1162, 1987.

5. Thoenen H, Bandtlow C and Heumann R: The physiological function of nerve growth factor in the central nervous system: Comparison with the periphery. Rev Physiol Biochem Pharmacol 109: 145-178, 1987.

6. Barde YA: Neurotrophins: A family of proteins supporting the survival of neurons. Prog Clin Biol Res 390: 45-56, 1994.

7. Sofroniew MV, Howe CL and Mobley WC: Nerve growth factor signaling, neuroprotection, and neural repair. Annu Rev Neurosci 24: 1217-1281, 2001.

8. Korsching S, Auburger G, Heumann R, Scott J and Thoenen H: Levels of nerve growth factor and its mRNA in the central nervous system of the rat correlate with cholinergic innervation. Embo J 4: 1389-1393, 1985.

9. Connor B and Dragunow M: The role of neuronal growth factors in neurodegenerative disorders of the human brain. Brain Res Brain Res Rev 27: 1-39, 1998.

10. Levi-Montalcini A and Angeletti PU: Nerve growth factor. Physiol Rev 48: 534-569, 1968.

11. Chao MV and Hempstead BL: p75 and Trk: A two-receptor system. Trends Neurosci 18: 321-326, 1995.

12. Zhang Z, Yang Y, Gong A, Wang C, Liang Y and Chen Y: Localization of NGF and TrkA at mitotic apparatus in human astrocytoma cell line u251. Biochem Biophys Res Commun 337: 68-74, 2005.

13. Friedman WJ, Ibáñez CF, Hallböök F, Persson H, Cain LD, Dreyfus CF and Black IB: Differential actions of neurotrophins in the locus corelueus and basal forebrain. Exp Neurol 119: 72-78, 1993.

14. Mamounas LA, Blue ME, Siuciak JA and Altar CA: Brain-derived neurotrophic factor promotes the survival and sprouting of serotonergic axons in rat brain. J Neurosci 15: 7929-7939, 1995.

15. Siuciak JA, Altar CA, Wiegand SJ and Lindsay RM: Antinociceptive effect of brain-derived neurotrophic factor and neurotrophin-3. Brain Res 633: 326-330, 1994.

16. Sklair-Tavron L and Nestler EJ: Opposing effects of morphine and the neurotrophins, NT-3, NT-4, and BDNF, on locus coeruleus neurons in vitro. Brain Res 702: 117-125, 1995.

17. Juric DM, Miklic S and Carman-Krzan M: Monoaminergic neuronal activity up-regulates BDNF synthesis in cultured neonatal rat astrocytes. Brain Res 1108: 54-62, 2006.

18. Baloh RH, Enomoto H, Johnson EM Jr and Milbrandt J: The GDNF family ligands and receptors-implications for neural development. Curr Opin Neurobiol 10: 103-110, 2000.

19. Yang ZF, Ho DW, Lau CK, Tam KH, Lam CT, Yu WC, Poon RT and Fan ST: Significance of the serum brain-derived neurotrophic factor and platelets in hepatocellular carcinoma. Oncol Rep 16: 1237-1243, 2006. 
20. Tapia-Arancibia L, Rage F, Givalois L and Arancibia S: Physiology of BDNF: Focus on hypothalamic function. Front Neuroendocrinol 25: 77-107, 2004.

21. Matsumoto K, Yamamoto K, Karasawa Y, Hino N, Nakamura A, Takahashi M, Araki H, Okuyama S, Choshi T, Sugino E, et al: Possible involvement of induction of brain-derived neurotrophic factor in the neuroprotective effect of a 5-phenylpyrimidine derivative. Biochem Pharmacol 66: 1019-1023, 2003.

22. Renné C, Willenbrock K, Küppers R, Hansmann ML and Bräuninger A: Autocrine and paracrine-activated receptor tyrosine kinases in classic hodgkin lymphoma. Blood 105 : 4051-4059, 2005.

23. Pearse RN, Swendeman SL, Li Y, Rafii D and Hempstead BL: A neurotrophin axis in myeloma: TrkB and BDNF promote tumor-cell survival. Blood 105: 4429-4436, 2005.

24. Douma S, Van Laar T, Zevenhoven J, Meuwissen R, Van Garderen E and Peeper DS: Suppression of anoikis and induction of metastasis by the neurotrophic receptor TrkB Nature 430: 1034-1039, 2004.

25. Grotzer MA, Janss AJ, Fung K, Biegel JA, Sutton LN, Rorke LB, Zhao H, Cnaan A, Phillips PC, Lee VM and Trojanowski JQ: TrkC expression predicts good clinical outcome in primitive neuroectodermal brain tumors. J Clin Oncol 18: 1027-1035, 2000

26. Segal RA, Goumnerova LC, Kwon YK, Stiles CD and Pomeroy SL: Expression of the neurotrophin receptor TrkC is linked to a favorable outcome in medulloblastoma. Proc Nat Acad Sci USA 91: 12867-12871, 1994.

27. Chiappa SA, Chin LS, Zurawel RH and Raffel C: Neurotrophins and Trk receptors in primitive neuroectodermal tumor cell lines. Neurosurgery 45: 1148-1155, 1999.

28. Colucci-D'Amato GL, D'Alessio A, Califano D, Cali G, Rizzo C, Nitsch L, Santelli G and de Franciscis V: Abrogation of nerve growth factor-induced terminal differentiation by ret oncogene involves perturbation of nuclear translocation of ERK. J Biol Chem 275: 19306-19314, 2000.

29. Devouassoux-Shisheboran M, Mauduit C, Tabone E, Droz JP and Benahmed M: Growth regulatory factors and signalling proteins in testicular germ cell tumours. APMIS 111: 212-224, 2003.
30. Eggert A, Sieverts H, Ikegaki N and Brodeur GM: P75 mediated apoptosis in neuroblastoma cells is inhibited by expression of TrkA. Med Pediatr Oncol 35: 573-576, 2000.

31. Goustin AS, Leof EB, Shipley GD and Moses HL: Growth factors and cancer. Cancer Res 46: 1015-1029, 1986

32. Nishio S, Morioka T, Hamada Y, Fukui M and Nakagawara A: Immunohistochemical expression of tyrosine kinase (Trk) receptor proteins in mature neuronal cell tumors of the central nervous system. Clin Neuropathol 17: 123-130, 1998.

33. Zhu Z, Friess H, diMola FF, Zimmermann A, Graber HU, Korc M and Büchler MW: Nerve growth factor expression correlates with perineural invasion and pain in human pancreatic cancer. J Clin Oncol 17: 2419-2428, 1999.

34. Zhu ZW, Friess H, Wang L, Di Mola FF, Zimmermann A and Büchler MW: Down-regulation of nerve growth factor in poorly differentiated and advanced human esophageal cancer. Anticancer Res 20: 125-132, 2000.

35. Dollé L, El Yazidi-Belkoura I, Adriaenssens E, Nurcombe V and Hondermarck H: Nerve growth factor overexpression and autocrine loop in breast cancer cells. Oncogene 22: 5592-5601, 2003.

36. Breit S, Ashman K, Wilting J, Rössler J, Hatzi E, Fotsis T and Schweigerer L: The N-myc oncogene in human neuroblastoma cells: Down-regulation of an angiogenesis inhibitor identified as activin. Cancer Res 60: 4596-4601, 2000.

37. Zhang J, Zhang J, Li A and Fan Y: Role of nerve growth factor receptor in neuroblastoma angiogenesis. Chinese J Contemporary Pediatrics 6: 93-98, 2004

38. Hu Y, Sun CY, Wang HF, Guo T, Wei WN, Wang YD, He WJ, Wu T, Tan $\mathrm{H}$ and Wu TC: Brain-derived neurotrophic factor promotes growth and migration of multiple myeloma cells. Cancer Genet Cytogenet 169: 12-20, 2006.

39. Qiu L Zhou C, Sun Y, Di W, Scheffler E, Healey S, Kouttab N, Chu W and Wan Y: Crosstalk between EGFR and TrkB enhances ovarian cancer cell migration and proliferation. Int J Oncol 29: 1003-1011, 2006 